\title{
Predictive Utility of Body Mass Index for Metabolic Syndrome Among Patients with Schizophrenia in
} Japan

This article was published in the following Dove Press journal: Neuropsychiatric Disease and Treatment

\author{
Norio Sugawara $\mathbb{D}^{1,2}$ \\ Norio Yasui-Furukori (iD) ${ }^{1,2}$ \\ Manabu Yamazaki ${ }^{3}$ \\ Kazutaka Shimodal,2 \\ Takao Mori ${ }^{3}$ \\ Takuro Sugai ${ }^{2,4}$ \\ Hiroshi Matsuda ${ }^{3}$ \\ Yutaro Suzuki ${ }^{2,4}$ \\ Yuji Ozeki ${ }^{2,5}$ \\ Kurefu Okamoto ${ }^{3}$ \\ Toyoaki Sagae 3,6 \\ Toshiyuki Someya ${ }^{2,4}$ \\ 'Department of Psychiatry, Dokkyo \\ Medical University School of Medicine, \\ Mibu, Tochigi 32I-0293, Japan; ${ }^{2} J a p a n e s e$ \\ Society of Clinical \\ Neuropsychopharmacology, Chiyoda-ku, \\ Tokyo I0I-0003, Japan; ${ }^{3}$ Japan Psychiatric \\ Hospital Association, Minato-ku, Tokyo \\ 108-8554, Japan; ${ }^{4}$ Department of \\ Psychiatry, Graduate School of Medical \\ and Dental Sciences, Niigata University, \\ Chuo-ku, Niigata 95I-85I0, Japan; \\ ${ }^{5}$ Department of Psychiatry, Shiga \\ University of Medical Science, Otsu, Shiga \\ 520-2134, Japan; ${ }^{6}$ Department of Health \\ and Nutrition, Yamagata Prefectural \\ Yonezawa University of Nutrition \\ Sciences, Yonezawa, Yamagata 992-0025, \\ Japan
}

Correspondence: Norio Sugawara Department of Psychiatry, Dokkyo Medical University School of Medicine, 880 Kitakobayashi, Mibu, Tochigi 32I0293, Japan

Tel +8I-28-287-2I53 (extension: 7|4I)

$\mathrm{Fax}+8 \mathrm{I}-28-286-5187$

Email nsuga3@dokkyomed.ac.jp
Background: Reliable and easy screening for metabolic syndrome (MetS) is important for patients with schizophrenia. The aim of this study was to assess the predictive utility of body mass index (BMI) for MetS among patients with schizophrenia in Japan.

Methods: In total, 8468 patients (4705 males, 3763 females) with schizophrenia or schizoaffective disorders based on the Diagnostic and Statistical Manual of Mental Disorders, fourth edition (DSM-IV), or the International Classification of Diseases, tenth revision (ICD10), were assessed for MetS using the criteria of the National Cholesterol Education Program Adult Treatment Panel III (ATP III-A). We applied a stratum-specific likelihood ratio (SSLR) analysis, which is independent of the prevalence of the target disease.

Results: The mean ( \pm standard deviation) age of these patients was $57.4 \pm 13.5$ years. The prevalence of MetS was 20.4\%. Among males, the SSLRs predicting MetS were 0.03 (95\% CI $0.02-0.06), 0.54$ (95\% CI $0.48-0.60), 2.77$ (95\% CI 2.44-3.14) and 8.75 (95\% CI $7.40-10.36$ ) for BMI $<20 \mathrm{~kg} / \mathrm{m}^{2}, 20 \mathrm{~kg} / \mathrm{m}^{2} \leq$ BMI $<25 \mathrm{~kg} / \mathrm{m}^{2}, 25 \mathrm{~kg} / \mathrm{m}^{2} \leq$ BMI $<28 \mathrm{~kg} /$ $\mathrm{m}^{2}$, and $28 \mathrm{~kg} / \mathrm{m}^{2} \leq \mathrm{BMI}$, respectively. For females, the SSLRs predicting MetS were 0.08 (95\% CI 0.05-0.12), 0.73 (95\% CI 0.66-0.82), 2.50 (95\% CI 2.16-2.90) and 4.83 (95\% CI 4.12-5.67) for the same BMI categories, respectively.

Conclusion: The predictive utility of BMI is confirmed, and BMI has more predictive value in males than in females. Patients with a BMI of $28 \mathrm{~kg} / \mathrm{m}^{2}$ or greater had a significantly higher SSLR than those with a BMI less than $28 \mathrm{~kg} / \mathrm{m}^{2}$.

Keywords: body mass index, metabolic syndrome, schizoaffective disorder, schizophrenia

\section{Introduction}

People with schizophrenia have an elevated mortality rate, which is more than 2 times as high as that in the general population. ${ }^{1}$ This mortality gap, which converts to $11-18$ years of potential life lost, ${ }^{2}$ has increased in recent decades. ${ }^{1,3}$ Most of the excess deaths are from natural causes, and the leading cause of death for patients with schizophrenia is cardiovascular disease (CVD). ${ }^{4,5}$ Recent meta-analysis estimated that the pooled prevalence of MetS is $32.5 \%$ among patients with schizophrenia. ${ }^{6}$ Two studies conducted in Japan, found a higher prevalence of metabolic syndrome (MetS) in patients with schizophrenia $(20.0 \sim 27.5 \%)$ than in the general population $(14.1 \sim 15.6 \%){ }^{7,8}$ MetS, which is defined as a cluster of metabolic disturbances, including abdominal obesity, atherogenic dyslipidemia, hypertension and hyperglycemia, ${ }^{9}$ has been related to an increased risk for CVD and mortality. ${ }^{10}$ Although cardiovascular risk increases after first exposure to any antipsychotic drug, ${ }^{11}$ the prevalence of MetS is significantly lower in patients with early 
schizophrenia than in those with an established diagnosis who are taking antipsychotic medication. ${ }^{12}$ The causes of adverse metabolic events are complicated; however, the risk factors among patients with schizophrenia are attributed to antipsychotic medications, ${ }^{13,14}$ dietary habits, ${ }^{15,16}$ negative symptoms of schizophrenia, ${ }^{17}$ physical activity, ${ }^{18}$ and unfavorable body composition. ${ }^{19}$ Although antipsychotic medications typically alleviate positive symptoms and delay relapse, ${ }^{20,21}$ metabolic side-effects are particularly common in patients treated with second-generation antipsychotics (SGA), especially clozapine and olanzapine. $^{22}$

Given the association between MetS and mortality, screening for and treating adverse metabolic events have been proposed as one approach to prevent excess deaths. However, a non-negligible number of patients do not wish to undergo blood tests, ${ }^{23}$ and the low rates of clinical monitoring and diagnosis of MetS might reflect the cost and discomfort associated with full physical and laboratory evaluations. ${ }^{24}$ To reduce the economic and physical burdens on patients, sequential testing, which consists of the first-stage selection of patients at higher risk by a convenient measure and the second-stage full evaluation of patients identified in the first stage to diagnose MetS, might be suitable in a real clinical setting. The first stage of sequential testing for MetS requires alternative reliable and easily obtainable screening measures.

To date, body mass index (BMI) has been proposed to be potentially useful in the prediction of MetS in various populations with or without schizophrenia. ${ }^{25-27}$ Although interpreting BMI as a continuous variable is informative, employing score categories with high predictive values could be clinically useful. To obtain such categories, the application of stratum-specific likelihood ratios (SSLRs) has been recognized as a more convenient and generalizable method. ${ }^{28-30}$ However, there have been few reports regarding the use of SSLR analysis to use BMI to screen for MetS among patients with schizophrenia.

The objective of this study was to determine the BMI categories that have predictive clinical value for clinical screening for MetS among patients with schizophrenia in Japan. We aimed to identify an inexpensive, easy-to-use screening criterion that could detect probable patients with MetS.

\section{Methods}

\section{Participants}

The joint committee of the Japanese Society of Clinical Neuropsychopharmacology and the Japan Psychiatric
Hospital Association for antipsychotic treatment and physical risk conducted this survey between January 2012 and July 2014. ${ }^{8}$ We obtained 7655 (outpatients) and 15,461 (inpatients) answers from 520 facilities for outpatients and 247 facilities for inpatients belonging to the Japan Psychiatric Hospital Association. We excluded individuals aged $<20$ years and whose sex was not assessed in the survey $(\mathrm{n}=738)$. We also excluded individuals who could not be assessed for MetS or BMI $(n=13,910)$. We analyzed a final total of 8468 subjects (2641 outpatients and 5827 inpatients; 4705 males and 3763 females) with schizophrenia or schizoaffective disorders based on the Diagnostic and Statistical Manual of Mental Disorders, fourth edition (DSM-IV), or the International Classification of Diseases, tenth revision (ICD-10). The proportion of current smokers was $27.2 \%$. The mean dose of antipsychotics was 678 $\pm 609 \mathrm{mg}$ /day chlorpromazine equivalent. ${ }^{31}$ Of the 8468 participants in this study, 3600 were receiving antipsychotic monotherapy, and 6514 were taking SGAs. The survey and procedure for obtaining informed consent were approved by the Ethics Committee at the Japan Psychiatric Hospitals Association. All participants provided verbal informed consent to participate in the study, without any incentive. The capacity of the patients to provide informed consent was assessed by their treating psychiatrists. A surrogate consent procedure was not employed in this study. This study was conducted in accordance with the Declaration of Helsinki. The characteristics of the study population have been reported previously [8]. In this study, we reanalyzed the subjects based on the categories of BMI.

\section{Measures}

Participant data including age, sex, height, and weight, were obtained from their medical records. Based on participants' height and weight, their BMIs were calculated. Waist circumference (WC), blood pressure (BP), triglyceride level (TG), high-density lipoprotein cholesterol (HDL) and fasting plasma glucose level (FPG) were also obtained from the medical records. The presence of MetS was determined based on the definitions given by the adapted Adult Treatment Panel III (ATP III-A) criteria proposed by the American Heart Association and the National Cholesterol Education Program. As detailed in the ATP III-A report, participants meeting $\geq 3$ of the following criteria were defined as having MetS: (1) abdominal obesity: WC $\geq$ $90 \mathrm{~cm}$ in men and $\geq 80 \mathrm{~cm}$ in women; (2) high BP: $\geq 130 /$ $85 \mathrm{mmHg}$; (3) low HDL: HDL < $40 \mathrm{mg} / \mathrm{dl}$ in men and < 
$50 \mathrm{mg} / \mathrm{dl}$ in women; (4) hypertriglyceridemia: $\mathrm{TG} \geq 150 \mathrm{mg} /$ $\mathrm{dl}$; and (5) high fasting glucose: $\mathrm{FPG} \geq 100 \mathrm{mg} / \mathrm{dl}$.

\section{Statistical Analysis}

The sensitivity, specificity, positive predictive value (PPV), and negative predictive value (NPV) were calculated for several cutoff scores of BMI. Receiver operating characteristic (ROC) analysis was performed, with the true-positive rate (sensitivity) plotted on the vertical axis and the falsepositive rate ( 1 - specificity) plotted on the horizontal axis; this approach allows the visualization of all pairs of sensitivity and specificity values achievable as the threshold is changed from a low score to a high score. The area under the curve (AUC) can be used as a quantitative indicator of the information content of a test: $1.00-0.90=$ excellent; 0.90 $0.80=$ good; $0.80-0.70=$ fair; $0.70-0.60=$ poor; and 0.60 $0.50=$ fail. ${ }^{32}$ In addition, the Youden index was used to determine the optimal cutoff BMI value that identified the presence of MetS. To compare the difference in two AUCs, we employed DeLong's test.

We computed the SSLRs and 95\% CIs using a program developed by Peirce and Cornell. An SSLR indicates how much more likely or less likely a specific test result is for individuals with a disease than for individuals without this disease; thus, this ratio could reveal the efficiency of a screening test. An LR of 5 or more indicates a moderate effect for the diagnosis of disease, and an LR of 5 increases the probability by $30 \%$ in clinical practice. ${ }^{32,33}$ To achieve the optimum number of strata, we followed the rules proposed by previous studies as follows: 1) provide sufficient disordered and nondisordered subjects in each stratum to allow the SSLRs to be monotonically related, and 2) collapse strata in which the SSLRs are close to one another and their $95 \%$ CIs easily overlap.

Logistic regression models were used to test whether the strata provided significantly more information than a single cutoff point. First, a logistic regression model with a dichotomous predictor was fitted. Then, a second model with the same dichotomous predictor and the strata as the categorical predictor was fitted. The difference between these two values was analyzed using the chi-square statistic under the null hypothesis that the strata predictor did not add more predictive ability than the single cutoff point. The software used for statistical analyses was $\mathrm{R}$ version 3.3.2. ${ }^{34}$

\section{Results}

The mean age of the study participants was $57.4 \pm 13.5$ (median 59.0), and the prevalence of MetS was 20.4\% (1730/8468). The sensitivities, specificities, PPVs, and NPVs are presented in Table 1. The ROC curve for BMI is depicted in Figure 1. The cutoff value, which was determined based on the Youden index, was $23.4 \mathrm{~kg} / \mathrm{m}^{2}$ (sensitivity $88.4 \%$, specificity $71.7 \%$, PPV $45.8 \%$, NPV $95.8 \%$ ) for males and $24.0 \mathrm{~kg} / \mathrm{m}^{2}$ for females (sensitivity $74.5 \%$, specificity $74.6 \%$, PPV $41.3 \%$, NPV $92.4 \%$ ). The AUC calculated using the ROC analysis was 0.88 (95\% CI $0.86-0.89)$ for males and 0.82 (95\% CI 0.80-0.83) for females. DeLong's test for the difference between two ROC curves showed a significant difference between males and females $(p<0.001)$.

The SSLR analysis results are indicated in Table 2. For males, the recommended SSLRs determined for MetS were 0.03 (95\% CI $0.02-0.06$ ), 0.54 (95\% CI $0.48-0.60), 2.77$ (95\% CI 2.44-3.14) and 8.75 (95\% CI 7.40-10.36) for the BMI categories of $<20 \mathrm{~kg} / \mathrm{m}^{2}, 20 \mathrm{~kg} / \mathrm{m}^{2} \leq \mathrm{BMI}<25 \mathrm{~kg} / \mathrm{m}^{2}$, $25 \mathrm{~kg} / \mathrm{m}^{2} \leq$ BMI $<28 \mathrm{~kg} / \mathrm{m}^{2}$, and $28 \mathrm{~kg} / \mathrm{m}^{2} \leq \mathrm{BMI}$,

Table I Sensitivity, Specificity, Positive Predictive Value and Negative Predictive Value of Body Mass Index in Relation to Metabolic Syndrome

\begin{tabular}{|c|c|c|c|c|c|c|c|c|}
\hline \multirow[t]{2}{*}{ Cut Off Point } & Sensitivity & Specificity & PPV & NPV & Sensitivity & Specificity & PPV & NPV \\
\hline & (\%) & (\%) & (\%) & (\%) & (\%) & (\%) & (\%) & (\%) \\
\hline & Male & & & & Female & & & \\
\hline $\mathrm{BMI} \geq 23$ & 90.7 & 67.5 & 43.0 & 96.4 & 83.3 & 66.0 & 37.1 & 94.3 \\
\hline $\mathrm{BMI} \geq 24$ & 83.6 & 76.8 & 49.3 & 94.5 & 74.3 & 74.6 & 41.2 & 92.4 \\
\hline $\mathrm{BMI} \geq 25$ & 71.2 & 83.9 & 54.4 & 91.5 & 65.2 & 80.8 & 44.9 & 90.6 \\
\hline $\mathrm{BMI} \geq 26$ & 60.6 & 89.8 & 61.7 & 89.4 & 52.8 & 86.3 & 48.1 & 88.4 \\
\hline $\mathrm{BMI} \geq 27$ & 49.6 & 93.3 & 66.6 & 87.2 & 44.2 & 89.6 & 50.5 & 87.0 \\
\hline $\mathrm{BMI} \geq 28$ & 38.8 & 95.6 & 70.3 & 85.2 & 35.5 & 92.6 & 53.7 & 85.7 \\
\hline $\mathrm{BMI} \geq 29$ & 29.8 & 96.9 & 72.2 & 83.6 & 28.0 & 94.4 & 54.4 & 84.5 \\
\hline $\mathrm{BMI} \geq 30$ & 21.7 & 98.0 & 74.8 & 82.2 & 20.7 & 96.1 & 56.1 & 83.5 \\
\hline
\end{tabular}

Abbreviations: PPV, positive predictive value; NPV, negative predictive value; BMI, body mass index. 


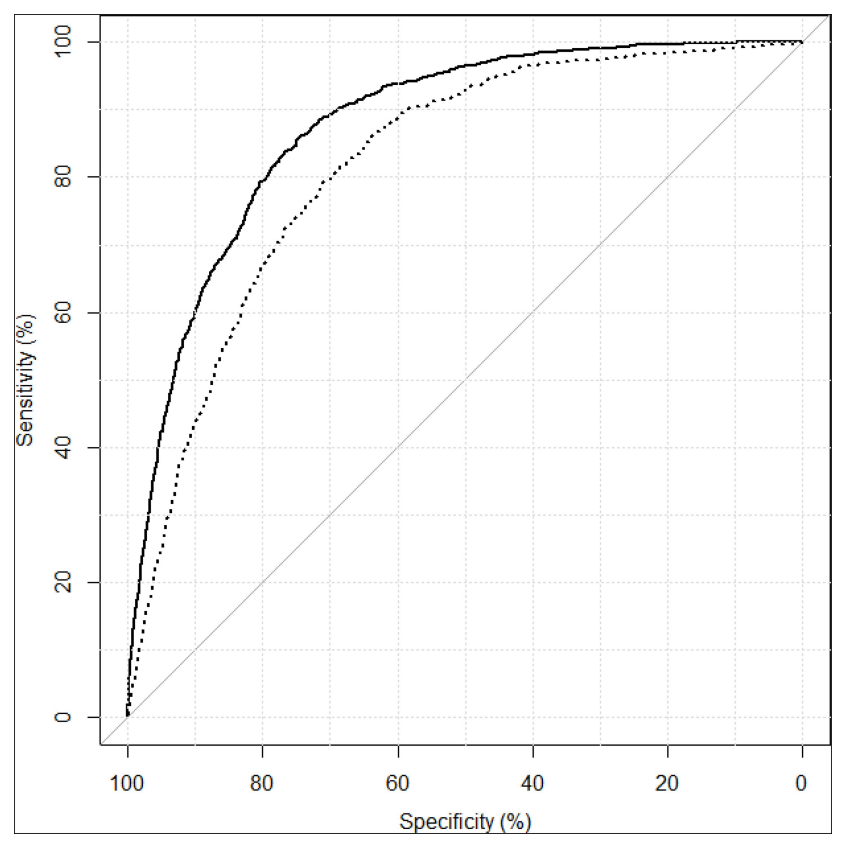

Figure I Receiver operating characteristic curve for metabolic syndrome and body mass index. The solid line is the male receiver operating characteristic curve; the dotted line is to the female receiver operating characteristic curve.

respectively. For females, the recommended SSLRs determined for MetS were 0.08 (95\% CI 0.05-0.12), 0.73 (95\% CI $0.66-0.82), 2.50$ (95\% CI 2.16-2.90) and 4.83 (95\% CI 4.12-5.67) for the same BMI categories, respectively.

In males, the $-2 \log$ LR for the model with a single cutoff point $(\mathrm{BMI}=23.4)$ for MetS was 3629 . The $-2 \cdot \log \mathrm{LR}$ for the model with the strata as a categorical predictor was 3495. The difference between these two values was 133.8 . The corresponding $\mathrm{p}$-value was small $(\mathrm{p}<0.001)$, indicating significant improvement when the BMI strata were used for predicting MetS. In females, the $-2 \log$ LR for the model with a single cutoff point $(\mathrm{BMI}=24.0)$ for predicting MetS was 3099 . The $-2 \cdot \log$ LR for the model with the strata as a categorical predictor was 1918 . The difference between these two values was 146.7. The corresponding $p$-value was small $(\mathrm{p}<0.001)$, indicating significant improvement when the strata were used for predicting MetS.

\section{Discussion}

In this study, BMI had an AUC value of more than 0.80, demonstrating that this scale has good validity for the detection of MetS in both male and female patients with schizophrenia. In addition, comparison of the AUC values between sexes shows that BMI is more predictive in males than in females. The cutoff values for BMI (males 23.4, females 24.0) based on the Youden index exhibited high sensitivity and specificity. However, the PPVs (males $45.8 \%$, females $41.3 \%$ ) for these cutoffs, which depend on the prevalence of the examined disease, indicate that more than half of the positive results obtained using this testing procedure are false positives. Given the prevalence of MetS in prior clinical studies, ${ }^{6,8}$ measures that are independent of the prevalence are needed for clinical screening.

We employed the SSLR approach, which is independent of the target disease prevalence, and obtained four BMI strata. By accounting for an individual's prior probability, this approach could provide a basis to calculate the posttest probability in each specific stratum. Our results demonstrated that a higher BMI was associated with a greater risk of MetS. Individuals with a BMI of $28 \mathrm{~kg} /$ $\mathrm{m}^{2}$ or greater had a significantly higher SSLR than those with BMI less than $28 \mathrm{~kg} / \mathrm{m}^{2}$. Relative to the other categories, these score categories will provide primary care physicians and psychiatrists with greater opportunities to detect individuals with MetS via further investigation following screening using BMI.

Table 2 Stratum-Specific Likelihood Ratios for Metabolic Syndrome

\begin{tabular}{|c|c|c|c|c|c|c|}
\hline & BMI & MetS (n) & Non MetS (n) & SSLR & $(95 \% \mathrm{Cl})$ & Posttest Probability (\%) \\
\hline \multicolumn{7}{|l|}{ Male } \\
\hline & $\mathrm{BMI}<20$ & II & 1196 & 0.03 & $(0.02-0.06)$ & 0.91 \\
\hline & $20 \leq \mathrm{BMI}<25$ & 277 & 1910 & 0.54 & $(0.48-0.60)$ & 12.67 \\
\hline & $25 \leq \mathrm{BMI}<28$ & 325 & 434 & 2.77 & $(2.44-3.14)$ & 42.82 \\
\hline & $28 \leq \mathrm{BMI}$ & 388 & 164 & 8.75 & $(7.40-10.36)$ & 70.29 \\
\hline \multicolumn{7}{|l|}{ Female } \\
\hline & $\mathrm{BMI}<20$ & 22 & 1137 & 0.08 & $(0.05-0.12)$ & 1.90 \\
\hline & $20 \leq \mathrm{BMI}<25$ & 232 & 1315 & 0.73 & $(0.66-0.82)$ & 15.00 \\
\hline & $25 \leq \mathrm{BMI}<28$ & 216 & 359 & 2.50 & $(2.16-2.90)$ & 37.57 \\
\hline & $28 \leq \mathrm{BMI}$ & 259 & 223 & 4.83 & $(4.12-5.67)$ & 53.73 \\
\hline
\end{tabular}

Abbreviations: BMI, body mass index; MetS, metabolic syndrome; SSLR, stratum-specific likelihood ratio; Cl, confidence interval. 
Previous studies investigating the predictive value of BMI for MetS have shown the LRs based on single cut-off points. Among 202 patients with schizophrenia, Tirupati and Chua identified a BMI $>28.7 \mathrm{~kg} / \mathrm{m}^{2}$ as the optimal cut-off using ROC analysis, and the LR for this criterion was 2.0. ${ }^{25}$ This result seems to indicate that the predictive value of BMI for MetS is small. However, all participants in the study had a Caucasian background. Differences in physique make it difficult to extrapolate from a population with European ancestry to a population of Japanese patients. Another study from Singapore conducted in 100 patients with schizophrenia reported an optimal BMI cutoff of $23 \mathrm{~kg} / \mathrm{m}^{2}$, and the LR was 1.8 , according to the reported sensitivity and specificity. ${ }^{26}$ Based on our results, the LR for the same BMI cut-off point of 23 is 2.8 . Although differences in participants' mean age and the analysis by sex might affect the results, the LRs based on single cut-off points have limited predictive value.

In line with the accumulating evidence of sex-based differences in physique and body composition, ${ }^{19}$ the MetS criteria have several components with different cut-off points by sex. The predictive value of BMI for MetS should be considered separately in males and females. Our past report showed that the odds ratio (OR) for the prediction of MetS by BMI is 1.57 for males and 1.42 for females, based on a logistic regression model. ${ }^{7}$ The OR of 1.57 indicates that for every increase in BMI of $1 \mathrm{~kg} / \mathrm{m}^{2}$, the estimated odds for MetS increased by $57 \%$. However, the risk of MetS could vary in different BMI categories (underweight, normal, overweight, and obesity), and estimation of risk using a single quantitative value is not appropriate. Furthermore, the prevalence of MetS in many previous studies, including ours, has been shown to be too high to interpret the OR as a risk ratio. ${ }^{6}$ In this study, we first applied SSLR analysis to screen for MetS with BMI among patients with schizophrenia. Based on the SSLRs of these four strata, the stratum with a BMI of $28 \mathrm{~kg} / \mathrm{m}^{2}$ or more has significant predictive value for MetS compared to the other three strata. The SSLRs of these four strata offer more information than the LRs of a single cut-off point and are more easily interpretable than ORs based on regression analysis.

Our results indicate that BMI has less predictive value in females than in males. In this study, we employed the ATP III-A criteria, which define abdominal obesity based on the cut-off point of a $\mathrm{WC} \geq 80 \mathrm{~cm}$ in women. Although abdominal (visceral) obesity has been regarded as the predominant risk factor for MetS, ${ }^{35}$ the optimal cut-off point for WC is controversial in Japan. In Japanese, a visceral fat area (VFA) greater than $100 \mathrm{~cm}^{2}$ on computed tomography at the umbilical level is correlated with the presence of cardiovascular risk factors, irrespective of age, sex, and BMI ${ }^{36,37}$ Because the WC corresponding to a VFA greater than $100 \mathrm{~cm}^{2}$ is over $90 \mathrm{~cm}$ in females, ${ }^{36,37}$ a definition based on the ATP III-A criteria could overestimate the prevalence of MetS in Japanese females. This overestimated prevalence of MetS in females might have affected our results.

In Japan, the prevalence of MetS is high in the middleaged population in the outpatient setting [8]. A complete assessment of all patients for MetS would be encouraged for this subgroup. BMI is reliably measured in the clinic and can be assessed with little training, so sequential testing is more cost effective and convenient in the case of assessing subgroups with a low prevalence of MetS. Furthermore, it is necessary to provide consistent treatment and follow-up after screening for MetS. Psychiatrists should be responsible for the management of MetS as well as the referral of patients to physicians. Switching antipsychotic medication to one with less potential to cause MetS or recommending nonpharmacological interventions such as nutrition education, exercise, and psychoeducation could improve metabolic abnormalities among patients with schizophrenia. ${ }^{38-40}$ Therefore, a combination of prompt detection and appropriate treatment is needed for effective clinical screening for MetS. Although a higher mean age (late 50s) might limit the generalizability of our results, this study has several strengths. Among studies that have investigated the LRs for the prediction of MetS by BMI, our study has the largest sample size, and the analysis stratified by sex could offer more clinically useful information.

This study has a few limitations. First, the participants may not be representative of the entire population of Japanese patients with schizophrenia. Since all of the participants were volunteers, they might be more interested in their health and be healthier than the entire population of patients. Second, the multicenter nature of this study, which was based on information obtained from medical records, could have affected the results. Although the procedures used to measure the physical and laboratory parameters were standardized, we could not completely rule out the possibility of inter-facility differences.

In conclusion, the predictive utility of BMI is confirmed, and BMI has more predictive value in males than in females. Patients with a BMI of $28 \mathrm{~kg} / \mathrm{m}^{2}$ or greater had a significantly higher SSLR than those with a BMI less than $28 \mathrm{~kg} / \mathrm{m}^{2}$. SSLR analysis is recommended due to its 
practical value for the detection of individuals at risk of MetS among Japanese patients with schizophrenia.

\section{Consent for Publication}

All participants provided verbal informed consent to participate in the study, without any incentive.

\section{Acknowledgments}

The authors would like to thank all of their coworkers for their skillful contributions to data collection and management.

\section{Author Contributions}

All authors designed this study. Dr. Sugawara analyzed the data and wrote the first draft of the manuscript. All authors contributed to data analysis, drafting or revising the article, gave final approval of the version to be published, and agree to be accountable for all aspects of the work. All authors have agreed on the journal to which the article will be submitted.

\section{Funding}

This work was partially supported by Eisai Co., Ltd.; Yoshitomi Pharmaceutical Industries; Dainippon Sumitomo Pharma Co., Ltd.; Astellas Pharma Inc.; Meiji Seika Pharma Co., Ltd.; Eli Lilly Japan K.K.; Otsuka Pharmaceutical Co., Ltd.; GlaxoSmithKline K.K.; Janssen Pharmaceutical K.K.; MSD K.K.; Shionogi \& Co., Ltd.; Asahi Kasei Pharma Corp.; Novartis Pharma Co., Ltd.; Takeda Pharmaceutical Co., Ltd.; Ono Pharmaceutical Co., Ltd.; and Tsumura \& Co. The funders had no role in the study design, data collection and analysis, decision to publish, or preparation of the manuscript.

\section{Disclosure}

T. Someya has received research support or honoraria from Asahi Kasei Pharma Corp; Astellas Pharma, Inc.; Daiichi Sankyo Co., Ltd.; Dainippon Sumitomo Pharma Co., Ltd.; Eisai Co., Ltd.; Eli Lilly Japan KK; GlaxoSmithKline KK; Janssen Pharmaceutical KK; Meiji Seika Pharma Co., Ltd.; Mitsubishi Tanabe Pharma Co., Ltd.; Mochida Pharmaceutical Co., Ltd.; MSD KK; Novartis Pharma KK; Otsuka Pharmaceutical Co., Ltd.; Pfizer Japan Inc; Shionogi \& Co., Ltd.; Sumitomo Dainippon Pharma Co., Ltd.; Tsumura \& Co.; and Yoshitomi Pharmaceutical Industries. Y. Suzuki has received research support or honoraria from Janssen Pharmaceutical KK; Mitsubishi Tanabe Pharma Co., Ltd.; and Otsuka Pharmaceutical
Co., Ltd. K. Shimoda has received research support or honoraria from Daiichi Sankyo Co., Ltd.; Dainippon Sumitomo Pharma Co., Ltd.; Eisai Co., Ltd.; Eli Lilly Japan KK; GlaxoSmithKline KK; Meiji Seika Pharma Co., Ltd.; Novartis Pharma KK; Otsuka Pharmaceutical Co., Ltd.; Pfizer Japan Inc; Shionogi \& Co., Ltd.; Takeda Pharmaceutical Co., Ltd.; Tsumra \& Co.; Yoshitomi Pharmaceutical Industries, Ltd.; Asahi Kasei Pharma Corporation; Astellas Pharma Inc; Janssen Pharmaceutical KK; Kowa Pharmaceutical Co., Ltd.; Meiji Seika Pharma Co.; Mitsubishi Tanabe Pharma Corporation, Ltd.; MSD KK; Novartis Pharma KK; and Ono Pharmaceutical Co., Ltd. K. Shimoda has received research support from Novartis Pharma K.K., Dainippon Sumitomo Pharma Co.; Astellas Pharma, Inc.; Meiji Seika Pharma Co., Ltd.; Eisai Co., Ltd.; Pfizer, Inc.; Otsuka Pharmaceutical Co., Ltd.; Daiichi Sankyo Co.; and Takeda Pharmaceutical Co., Ltd.; honoraria from Eisai Co., Ltd.; Mitsubishi Tanabe Pharma Corporation; Takeda Pharmaceutical Co., Ltd.; Meiji Seika Pharma Co., Ltd.; Janssen Pharmaceutical K.K.; Shionogi \& Co., Ltd.; Dainippon Sumitomo Pharma Co.; Daiichi Sankyo Co. and Pfizer, Inc. N. Yasui-Furukori has received research support or honoraria from Astellas Pharma, Inc.; Dainippon Sumitomo Pharma Co., Ltd.; Eli Lilly Japan KK; GlaxoSmithKline KK; Janssen Pharmaceutical KK; Meiji Seika Pharma Co.; Mochida Pharmaceutical Co., Ltd.; MSD KK; Otsuka Pharmaceutical Co., Ltd.; Pfizer Japan, Inc.; Takeda Pharmaceutical Co., Ltd.; and Yoshitomi Pharmaceutical Industries. N. Sugawara has received grant/research support from the Grant-in-Aid for Young Scientists (B); the Ministry of Education, Culture, Sports, Science and Technology, Japan Grant B; the Karoji Memorial Fund for Medical Research Grant; and the SENSHIN Medical Research Foundation. Y Ozeki reports grants from Eisai Co., Ltd. There are no patents, products in development, or marketed products to declare. This does not alter the authors' adherence to all the General Hospital Psychiatry policies on sharing data and materials, as detailed online in the guide for authors. The other authors declare no potential conflicts of interest.

\section{References}

1. Walker ER, McGee RE, Druss BG. Mortality in mental disorders and global disease burden implications: a systematic review and meta-analysis. JAMA Psychiatry. 2015;72(4):334-341. doi:10.1001/ jamapsychiatry.2014.2502

2. Hjorthøj C, Stürup AE, McGrath JJ, Nordentoft M. Years of potential life lost and life expectancy in schizophrenia: a systematic review and 
meta-analysis. Lancet Psychiatry. 2017;4(4):295-301. doi:10.1016/ S2215-0366(17)30078-0

3. Nielsen RE, Uggerby AS, Jensen SOW, McGrath JJ. Increasing mortality gap for patients diagnosed with schizophrenia over the last three decades-a danish nationwide study from 1980 to 2010 . Schizophr Res. 2013;146(1-3):22-27. doi:10.1016/j.schres.2013.02. 025

4. Olfson M, Gerhard T, Huang C, Crystal S, Stroup TS. Premature mortality among adults with schizophrenia in the United States. JAMA Psychiatry. 2015;72(12):1172-1181. doi:10.1001/jamapsychiatry.2015. 1737

5. Brown S, Kim M, Mitchell C, Inskip H. Twenty-five year mortality of a community cohort with schizophrenia. Br J Psychiatry. 2010;196 (2):116-121. doi:10.1192/bjp.bp.109.067512

6. Mitchell AJ, Vancampfort D, Sweers K, van Winkel R, Yu W, De Hert M. Prevalence of metabolic syndrome and metabolic abnormalities in schizophrenia and related disorders-a systematic review and meta-analysis. Schizophr Bull. 2013;39(2):306-318. doi:10.1093/ schbul/sbr 148

7. Sugawara N, Yasui-Furukori N, Sato Y, et al. Prevalence of metabolic syndrome among patients with schizophrenia in Japan. Schizophr Res. 2010;123(2-3):244-250. doi:10.1016/j.schres.2010.08.030

8. Sugai T, Suzuki Y, Yamazaki M, et al. Difference in prevalence of metabolic syndrome between Japanese outpatients and inpatients with schizophrenia: a nationwide survey. Schizophr Res. 2016;171 (1-3):68-73. doi:10.1016/j.schres.2016.01.016

9. Grundy SM. Hypertriglyceridemia, insulin resistance, and the metabolic syndrome. Am J Cardiol. 1999;83(9B):25F-29F. doi:10.1016/ s0002-9149(99)00211-8

10. Mottillo S, Filion KB, Genest J, et al. The metabolic syndrome and cardiovascular risk a systematic review and meta-analysis. $J$ Am Coll Cardiol. 2010;56(14):1113-1132. doi:10.1016/j.jacc.2010.05.034

11. Foley DL, Morley KI. Systematic review of early cardiometabolic outcomes of the first treated episode of psychosis. Arch Gen Psychiatry. 2011;68(6):609-616. doi:10.1001/archgenpsychiatry.20 11.2

12. Mitchell AJ, Vancampfort D, De Herdt A, Yu W, De Hert M. Is the prevalence of metabolic syndrome and metabolic abnormalities increased in early schizophrenia? A comparative meta-analysis of first episode, untreated and treated patients. Schizophr Bull. 2013;39 (2):295-305. doi:10.1093/schbul/sbs082

13. Yasui-Furukori N, Sato Y, Furukori H, Saito M, Nakagami T, Kaneko S. Glucose metabolism in Japanese schizophrenia patients treated with risperidone or olanzapine. J Clin Psychiatry. 2009;70 (1):95-100. doi: $10.4088 / \mathrm{jcp} .07 \mathrm{~m} 03829$

14. Sugai T, Suzuki Y, Fukui N, et al. Dysregulation of adipocytokines related to second-generation antipsychotics in normal fasting glucose patients with schizophrenia. J Clin Psychopharmacol. 2012;32 (3):390-393. doi:10.1097/JCP.0b013e3182524393

15. Dipasquale S, Pariante CM, Dazzan P, Aguglia E, McGuire P, Mondelli V. The dietary pattern of patients with schizophrenia: a systematic review. J Psychiatr Res. 2013;47(2):197-207. doi:10.1016/j.jpsychires.2012.10.005

16. Sugawara N, Yasui-Furukori N, Sato Y, et al. Dietary patterns are associated with obesity in Japanese patients with schizophrenia. BMC Psychiatry. 2014;14(1):184. doi:10.1186/1471-244X-14-184

17. Sicras-Mainar A, Maurino J, Ruiz-Beato E, Navarro-Artieda R. Prevalence of metabolic syndrome according to the presence of negative symptoms in patients with schizophrenia. Neuropsychiatr Dis Treat. 2014;11:51-57. doi:10.2147/NDT.S75449

18. Vancampfort D, Probst M, Scheewe T, et al. Relationships between physical fitness, physical activity, smoking and metabolic and mental health parameters in people with schizophrenia. Psychiatry Res. 2013;207(1-2):25-32. doi:10.1016/j.psychres.2012.09.026
19. Sugawara N, Yasui-Furukori N, Tsuchimine S, et al. Body composition in patients with schizophrenia: comparison with healthy controls. Ann Gen Psychiatry. 2012;11(1):11. doi:10.1186/1744-859X-11-11

20. Yasui-Furukori N, Kondo T, Ishida M, et al. Therapeutic effects of bromperidol on the five dimensions of schizophrenic symptoms. Prog Neuropsychopharmacol Biol Psychiatry. 2002;26(1):53-57. doi:10. 1016/s0278-5846(01)00218-4

21. Rui Q, Wang Y, Liang S, et al. Relapse prevention study of paliperidone extended-release tablets in Chinese patients with schizophrenia. Prog Neuropsychopharmacol Biol Psychiatry. 2014;53:45-53. doi:10.1016/j.pnpbp.2014.02.007

22. Pillinger T, McCutcheon RA, Vano L, et al. Comparative effects of 18 antipsychotics on metabolic function in patients with schizophrenia, predictors of metabolic dysregulation, and association with psychopathology: a systematic review and network meta-analysis. Lancet Psychiatry. 2020;7(1):64-77. doi:10.1016/S2215-0366(19)30416-X

23. Sugawara N, Yasui-Furukori N, Yamazaki M, et al. Attitudes toward metabolic adverse events among patients with schizophrenia in Japan. Neuropsychiatr Dis Treat. 2016;12:427-436. doi:10.2147/ NDT.S98711

24. Sugawara N, Yasui-Furukori N, Yamazaki M, et al. Psychiatrists' attitudes toward metabolic adverse events in patients with schizophrenia. PLoS One. 2014;9(1):e86826. doi:10.1371/journal.pone.0086826

25. Tirupati CLE. Body mass index as a screening test for metabolic syndrome in schizophrenia and schizoaffective disorders. Australas Psychiatry. 2007;15(6):470-473. doi:10.1080/10398560701636906

26. Nurjono M, Lee J. Predictive utility of blood pressure, waist circumference and body mass index for metabolic syndrome in patients with schizophrenia in Singapore. Early Interv Psychiatry. 2013;7 (2):205-209. doi:10.1111/j.1751-7893.2012.00384.x

27. Kawada T, Otsuka T, Inagaki H, et al. Optimal cut-off levels of body mass index and waist circumference in relation to each component of metabolic syndrome (MetS) and the number of MetS component. Diabetes Metab Syndr. 2011;5(1):25-28. doi:10.1016/j.dsx.2010.05.012

28. Peirce JC, Cornell RG. Integrating stratum-specific likelihood ratios with the analysis of ROC curves. Med Decis Making. 1993;13 (2):141-151. doi:10.1177/0272989X9301300208

29. Schmitz N, Kruse J, Tress W. Application of stratum-specific likelihood ratios in mental health screening. Soc Psychiatry Psychiatr Epidemiol. 2000;35(8):375-379. doi:10.1007/s001270050253

30. Sugawara N, Kaneda A, Takahashi I, Nakaji S, Yasui-Furukori N. Application of a stratum-specific likelihood ratio analysis in a screen for depression among a community-dwelling population in Japan. Neuropsychiatr Dis Treat. 2017;13:2369-2374. doi:10.2147/NDT. S142517

31. Inada $\mathrm{T}$, Inagaki A. Psychotropic dose equivalence in Japan. Psychiatry Clin Neurosci. 2015;69(8):440-447. doi:10.1111/pcn.12275

32. Katon W, Russo J, Richardson L, McCauley E, Lozano P. Anxiety and depression screening for youth in a primary care population. Ambul Pediatr. 2008;8(3):182-188. doi:10.1016/j.ambp.2008.01.003

33. McGee S. Simplifying likelihood ratios. J Gen Intern Med. 2002;17 (8):646-649. doi:10.1046/j.1525-1497.2002.10750.x

34. Venables WN, Smith DM, The R Core Team. An Introduction to R, Notes on R: A Programming Environment for Data Analysis and Graphics Version 3.3.2; 2016

35. Paley CA, Johnson MI. Abdominal obesity and metabolic syndrome: exercise as medicine? BMC Sports Sci Med Rehabil. 2018;10:7. doi:10.1186/s13102-018-0097-1

36. Examination Committee of Criteria for 'Obesity Disease' in Japan. Japan Society for the study of obesity. New criteria for 'obesity disease' in Japan. Circ J. 2002;66(11):987-992. doi:10.1253/circj.66.987.

37. Hiuge-Shimizu A, Kishida K, Funahashi T, et al. Absolute value of visceral fat area measured on computed tomography scans and obesity-related cardiovascular risk factors in large-scale Japanese general population (the VACATION-J study). Ann Med. 2012;44 (1):82-92. doi:10.3109/07853890.2010.526138 
38. Mukundan A, Faulkner G, Cohn T, Remington G. Antipsychotic switching for people with schizophrenia who have neuroleptic-induced weight or metabolic problems. Cochrane Database Syst Rev. 2010;12: CD006629. doi:10.1002/14651858.CD006629.pub2

39. Caemmerer J, Correll CU, Maayan L. Acute and maintenance effects of non-pharmacologic interventions for antipsychotic associated weight gain and metabolic abnormalities: a meta-analytic comparison of randomized controlled trials. Schizophr Res. 2012;140(1-3):159-168. doi:10.1016/j.schres.2012.03.017

40. Sugawara N, Sagae T, Yasui-Furukori N, et al. Effects of nutritional education on weight change and metabolic abnormalities among patients with schizophrenia in Japan: a randomized controlled trial. J Psychiatr Res. 2018;97:77-83. doi:10.1016/j.jpsychires.2017. 12.002

\section{Publish your work in this journal}

Neuropsychiatric Disease and Treatment is an international, peerreviewed journal of clinical therapeutics and pharmacology focusing on concise rapid reporting of clinical or pre-clinical studies on a range of neuropsychiatric and neurological disorders. This journal is indexed on PubMed Central, the 'PsycINFO' database and CAS, and is the official journal of The International Neuropsychiatric Association (INA). The manuscript management system is completely online and includes a very quick and fair peer-review system, which is all easy to use. Visit http://www.dovepress.com/testimonials.php to read real quotes from published authors. 